\title{
A ENTREVISTA COM OS PAIS NA TERAPIA DO ESPECTRO AUTÍSTICO
}

\section{Interview with parents in autistic spectrum therapy}

\author{
Michele Paula Moro (1), Ana Paula Ramos de Souza (2)
}

\begin{abstract}
RESUMO
Tema: entrevistas continuadas com mães e pais de sujeitos com espectro autístico no processo terapêutico em Fonoaudiologia. Procedimentos: as entrevistas com os pais dos sujeitos foram feitas quinzenalmente por 24 meses consecutivos e o conteúdo foi anotado logo após sua realização, para análise posterior. Os dados foram analisados considerando o contexto global de cada caso. Resultados: o espaço aberto pelas entrevistas continuadas foi fundamental para que os pais debatessem suas dúvidas sobre as limitações dos filhos e para que refletissem sobre aspectos como o brincar, a comunicação e o estabelecimento de limites com os filhos. Ou seja, os pais puderam refletir sobre o próprio exercício da função parental. Esse processo foi mais intenso no grupo de mães do que no de pais. Como efeito houve melhora dialógica e do brincar entre os pais e seus filhos. Conclusão: a entrevista continuada apresentou-se como aspecto fundamental do processo terapêutico realizado sob a perspectiva teórica que inclui a psicanálise e a concepção interacionista de aquisição da linguagem.
\end{abstract}

DESCRITORES: Fonoaudiologia; Entrevista; Linguagem; Comportamento Materno; Transtorno Autístico

\section{INTRODUÇÃO}

Tem-se observado, nas últimas décadas, 0 aumento da incidência de casos de autismo ${ }^{1-4}$, o que gera preocupação em relação à forma como tal diagnóstico tem sido realizado e como a notícia tem sido dada aos pais e/ou familiares de tais sujeitos.

Sabe-se, também, da importância de os profissionais estarem preparados para o trabalho simultâneo com o sujeito com autismo e sua família. É importante que a mesma faça o luto do filho imaginado, para que possa lidar com o filho real; o diagnóstico de "autista" causa grande angústia e frustração, vergonha e medo nos pais. Os pais, desamparados pela perda do filho perfeito, calam-se pela doença

(1) Fonoaudióloga da Clínica Meireles-Santa Maria e da Associação de Pais e Amigos do Excepcional - APAE, Tupanceretã; Mestranda em Distúrbios da Comunicação Humana na Universidade Federal de Santa Maria.

(2) Fonoaudióloga; Professora do Curso de Fonoaudiologia e do Programa de Pós-Graduação em Distúrbios da Comunicação Humana da Universidade Federal de Santa Maria; Doutora em Letras pela Pontifícia Universidade Católica do Rio Grande do Sul.

Conflito de interesses: inexistente e acabam esquecendo a criança e focando a patologia (autismo), em si, na relação com o filho ${ }^{5}$.

Há várias concepções de clínica fonoaudiológica junto ao autismo. A mais usual nos trabalhos internacionais e, em parcela dos nacionais, é a que enfoca o trabalho direto com o sujeito autista, com o acesso aos pais apenas na entrevista inicial e em entrevistas esporádicas para orientações ${ }^{6,7}$. Essa visão se relaciona a abordagens behavioristas ou cognitivas, baseadas na condição de desenvolvimento infantil exclusivamente dependente da construção da linguagem (aspecto fundamental da constituição do sujeito). O foco é, portanto, no comportamento lingüístico manifestado de modo que se acredita ser decorrente de um comprometimento orgânico . Como consequência, vários estudos, ainda, abordam a arquitetura neuropsicológica destes distúrbios, o papel da inteligência e a descrição das habilidades executadas por esses sujeitos ${ }^{6}$.

Embora tais aspectos sejam importantes, visto que há evidências de que realmente há um comprometimento orgânico nesses casos ${ }^{7}$, existem trabalhos que consideram a importância do papel da família na terapia do sujeito, destacando-se os 
trabalhos na perspectiva psicanalítica de subjetividade ${ }^{8}$. Tal visão corresponde à concepção de linguagem interacionista deslocada para a clínica dos distúrbios de linguagem relacionados ao espectro autístico ${ }^{9}$. Na combinação de tais perspectivas fica evidente a necessidade de se investigar o exercício das funções parentais em conjunto com o modo como o diálogo ocorre entre pais e filho ${ }^{10}$.

Para tanto, constitui-se como proposta terapêutica a escuta feita aos pais, que recebem acompanhamento em entrevistas continuadas, para poderem manifestar suas frustrações e tentativas de buscar um novo olhar em relação ao seu filho, esperando-se, com isso, que voltem a investir na comunicação ${ }^{11} \mathrm{e}$ em atividades lúdicas com ele ${ }^{12}$.

Considerando tais pressupostos, o objetivo deste artigo é analisar o papel das entrevistas continuadas na participação de mães e pais durante o processo terapêutico de seus filhos com diagnóstico de autismo.

\section{APRESENTAÇÃO DOS CASOS}

Trata-se de uma pesquisa qualitativa, exploratória e descritiva, na qual foram estudados três sujeitos, entre dois e quatro anos de idade cronológica, com diagnóstico de autismo, conforme os critérios estabelecidos pelo Manual de Diagnóstico e Estatística dos Distúrbios Mentais (DSM) - IV que são semelhantes ao Código de Classificação Internacional de Doenças (CID) - 10.

A amostra foi de conveniência, buscando-se os sujeitos mais jovens do serviço de atendimento fonoaudiológico da instituição de origem, no qual o trabalho foi realizado, tendo em vista a perspectiva de que a plasticidade cerebral tem papel fundamental no sucesso clínico. Outro critério, considerado neste trabalho, foi de os sujeitos não terem realizado terapia fonoaudiológica anterior, embora pudessem ter sido atendidos em outros espaços terapêuticos, como foi o caso de dois sujeitos ( $\mathrm{L}$ e C) que foram atendidos por educadora especial em abordagem comportamentalista.

Este estudo insere-se no projeto "Clínica da Subjetividade nos Retardos de Aquisição da Linguagem Oral: retardos de aquisição da linguagem oral secundários a grandes transtornos do desenvolvimento" aprovado no Comitê de Ética Institucional sob número 0117.0.243.000-07.

Inicialmente, serão apresentados o relato histórico dos princípios e das estratégias terapêuticas desenvolvidas e alguns dados dos sujeitos abordando-se a história pregressa e conteúdos das entrevistas continuadas realizadas com os pais.

Nos primeiros atendimentos, as mães dos três sujeitos com características do espectro autista que compõem esta amostra foram esclarecidas sobre os propósitos do estudo, assim com o direito de desistir de participar do mesmo, sem prejuízo ao tratamento do filho. Os procedimentos de coleta foram iniciados após a assinatura do Termo de Consentimento Livre e Esclarecido (TCLE), nos termos da aprovação do Comitê de Ética em Pesquisa Institucional.

Foram realizadas entrevistas continuadas com as mães e os pais que, além de ser uma forma de intervenção, foi uma forma de atualização e de complementação de dados sobre o exercício das funções parentais e os reflexos da intervenção terapêutica no ambiente familiar.

Tais entrevistas foram agendadas quinzenalmente no período de setembro de 2008 a junho de 2009, porém a presença variou de familiar para familiar. Em geral, houve um aumento das entrevistas, passando a semanal, em momentos críticos da terapia, conforme será descrito caso a caso. A presença dos pais ocorreu em menor escala para os casos $L$ e $C$ do que no caso de $A$. Já a presença das três mães foi assídua.

O conteúdo das entrevistas foi anotado e organizado na forma de relatório logo após a realização das mesmas. As entrevistas foram interpretadas a partir de uma análise psicanalítica do discurso materno e/ou paterno a partir das anotações realizadas pela terapeuta após cada encontro (não sendo gravadas em áudio e/ou imagem). Nos momentos mais críticos do processo terapêutico com os pais, as entrevistas foram feitas com a orientadora/supervisora do projeto e terapeuta responsável pelos atendimentos. A estratégia utilizada, em termos de método analítico, foi a leitura e releitura das anotações e das transcrições das entrevistas e recorte de temáticas que giravam, sobretudo, em relação às representações parentais sobre o filho real em contraposição ao imaginado, a autopercepção como pais e a percepção do processo fonoaudiológico pelos pais.

Para controle dos efeitos das entrevistas na interação com os filhos, além do atendimento direto com o sujeito, individual ou conjunto com a mãe, os três sujeitos (L, C, A) foram filmados durante a interação com a terapeuta (T) e com a mãe/pai (Mãe-L, Mãe-C e Mãe-A; e Pai-L, Pai-C e Pai-A) ao início dos atendimentos e ao final dos mesmos, no período de aproximadamente 10 meses (contado do início do procedimento terapêutico de cada sujeito). A terapia fonoaudiológica foi realizada com abordagem na perspectiva da clínica dos distúrbios de linguagem, orientada por uma visão teórica interacionista, em termos de aquisição da linguagem ${ }^{13}$, e por estudos psicanalíticos sobre o desenvolvimento infantil ${ }^{14}$. Levou-se em conta a intersubjetividade 
mãe-filho para o funcionamento de linguagem ${ }^{15}$. As sessões ocorreram duas vezes por semana, com duração de 30 a 45 minutos cada, esta variação de tempo dependia da aceitação do sujeito.

Algumas sessões (a primeira e uma por mês) foram filmadas com intuito de se analisar a interação da díade mãe-filho, ou pai-filho, nas quais se puderam observar as características dos sujeitos e de seus pais enquanto brincavam e as evoluções verificadas no período de atendimento. Tais evoluções foram verificadas para que subsidiassem as entrevistas continuadas, pois acredita-se que um bom processo terapêutico deve considerar, de modo dialético, o discurso dos pais em conjunto com as interações dos mesmos com seus filhos em sessão. Portanto, houve uma sintonia fina entre as entrevistas realizadas com os pais e o que se observava nas sessões de modo a maximizar os dois tipos de intervenção terapêutica.

Em todas as filmagens, foram colocados objetos próprios à faixa etária do sujeito na sala e foi solicitado à mãe e/ou pai que brincasse com o filho. Em relação aos sujeitos, observou-se a compreensão de linguagem durante a atividade lúdica, a forma de brincar deles. Os aspectos observados na conduta materna envolveram a entonação da mãe (de satisfação, insatisfação e desânimo), o uso ou não de entonação da fala dirigida pelo adulto a um bebê e que tem o poder de captar a atenção do último ${ }^{8,14}$, a troca de turnos pela mãe e filho, a capacidade dela se sintonizar com os gestos e/ou fala do filho e, assim, responder (ou não) às demandas do sujeito.

\section{Sujeito 1 (C)}

C. é um menino e estava com 4 anos e 6 meses quando compareceu à clínica fonoaudiológica com queixa principal de dificuldade na fala, depois de obter diagnóstico de espectro autista, comunicado à mãe por uma psicopedagoga na cidade de Santa Maria (educadora especial).

Durante o período gestacional, houve a necessidade de repouso, pois a mãe apresentou ameaça de aborto a partir do sexto mês de gravidez, acompanhada de perturbado estado emocional. O nascimento foi cesariana, a termo e sem intercorrência negativa. Foi informado que $\mathrm{C}$. dormia com os pais e estes observavam que ele apresentava sono muito agitado.

O desenvolvimento psicomotor ocorreu sem alterações. Quanto à linguagem, a mãe refere que, após o sexto mês, C. demonstrou balbucio e, próximo de um ano, surgiram as primeiras palavras ("mama, papa, tata"), seguindo-se de "não qué xixi" para "não quero fazer xixi". Não usou gestos para se comunicar.
Ao início da terapia, não fazia uso de pronomes, e o uso de frases simples era restrito, sendo as mesmas produzidas soltas e fora de contexto. Apresentava fala ecolálica, assim como alguns jargões e estereotipias de mãos (flapping).

Era comum, no brincar, a mãe observar alguns rituais como rodar as rodinhas dos carrinhos, tampas, etc. Ela o deixava brincar sozinho (C. apreciava essa situação) e, quando contrariado, apresentava crises de birra com tremores, atirando-se no chão. Muitas vezes, chorava sem motivo aparente.

\section{As entrevistas continuadas com os pais de $\mathbf{C}$}

Vindos de uma abordagem comportamental, esses pais chegaram ao atendimento fonoaudiológico com grande expectativa em relação ao desenvolvimento da comunicação do filho, já que os outros aspectos do desenvolvimento estavam sendo trabalhados com a educadora especial.

No primeiro encontro, a primeira das entrevistas continuadas, a mãe expõe sua idéia de como seria 0 atendimento fonoaudiológico baseando-se no exemplo das sessões terapêuticas realizadas pela educadora especial. Sua reação foi de surpresa ao ser informada de que ela estaria presente nas sessões e que a abordagem, com a qual trabalhávamos, preconizava a terapêutica com o brincar na díade mãe-sujeito. Pareceu um pouco descrente sobre o brincar, mas se disponibilizou, de imediato, a participar das sessões de intervenção e do acompanhamento realizado com as entrevistas continuadas.

Em cada entrevista, surgia um novo olhar em relação à terapia do filho com a sua participação, principalmente, pelo fato de ser uma terapia que se faz "brincando". Evidenciou sua resistência em participar das sessões, pois mencionava "achar que o certo era seguir as orientações do método comportamental, pois era como sabia e pensava que era o melhor a ser feito".

Os primeiros encontros enfocaram mais o fato de a gravidez de $\mathrm{C}$. não ter sido planejada. A mãe informou que precisou desistir de estudar, revelando momentos de tristeza; pensava não ser o momento certo para uma gravidez, embora tivesse planejado ter filhos com o marido.

Nas conversas seguintes, aproximadamente no início do quinto mês de acompanhamento, precisamente após dez entrevistas, surgiram as primeiras mudanças na forma de ver o filho. A mãe foi deixando de ver o "autista C." para observar "C. com características do espectro autístico". Seus relatos demonstravam descobertas pelo brincar, em que aproveitava o que observava nas terapias conjuntas para se inspirar em novas interações com o filho. Frequentemente, a mãe informava que "não imaginava que não sabia brincar e, que brincar era 
estar envolvida e presente na brincadeira do filho, no momento de vida do filho". Disse ter percebido a importância de "querer brincar verdadeiramente", de passar mais tempo com o filho, situação que pouco acontecia anteriormente, em função do trabalho. Pensava que, se oferecesse um brinquedo deixando o filho "brincar" e desse uma atenção rápida, era o suficiente. Muitas vezes, referiu estar descobrindo que aprendeu a brincar, pois, antes não pensava na importância desse momento tão simples: "(...) eu não sabia brincar".

As dúvidas iniciais sobre o futuro de C. e de como ele se comportaria nas séries escolares permaneciam. Essas questões sugeriam que a mãe ainda não acreditava na melhora, ou nas possibilidades de adequação do filho ao que é tido como "normalidade". Apesar disso, era notável o seu empenho para interpretar os enunciados do filho, demonstrando a ele que estava presente, procurando dar sentido para sua fala. Relatava situações nas quais C. "conversava"; disse que C. chamava sua atenção verbalmente e iniciara o relato de seu dia na escola, contando-lhe alguma situação, de forma ainda "enrolada", para a escuta da mãe, porém inteligível.

O pai estava cada dia mais presente, o que se confirmava na sua participação mais assídua nas terapias. As maiores reclamações tornaram-se referentes ao humor de $\mathrm{C}$. e suas crises de birra, que também eram vividas em terapia. No entanto, C., cada vez mais, deixava de ter características do espectro autístico e passava a brincar de modo simbólico e mais complexo. Sua fala evoluía para a produção de sentenças e ele participava de modo adequado no diálogo, tanto com os pais quanto com a terapeuta.

\section{Reflexos das entrevistas na interação com C}

De acordo com o relatado, o papel da terapeuta foi alertar a mãe, nas entrevistas continuadas ou por meio do modelo (em sessão), sobre a importância do se entregar ao brincar e de dialogar, sem a preocupação com ensinamento pedagógico.

Inicialmente, a mãe pareceu não se sentir à vontade para brincar com o filho, demonstrando certa apreensão pela forma como $\mathrm{C}$. utilizava os brinquedos. Parecia estar analisando cada movimento do filho, destacando o que percebia não ser adequado. Estas manifestações da mãe eram observadas pela terapeuta nos momentos em que a mãe interagia com o filho no decorrer de atividades com foco pedagógico. Esse mecanismo parecia relacionado ao processo terapêutico anterior (comportamentalista), o que foi muito discutido nas entrevistas, possibilitando a compreensão da mãe sobre a diferença daquela abordagem em relação ao brincar livre proposto nesta pesquisa.
O reflexo das mudanças que aconteciam na postura da mãe aparecia no comportamento de C. E ela, a cada sessão, demonstrava maior organização com o esclarecimento sobre o processo terapêutico e a diminuição de sua ansiedade. MC já participava do brincar com o filho sem tentar dirigir sua vontade, pois buscava entrar na brincadeira de C., dando interpretações sobre o que ele pudesse estar inventando. Sentia-se feliz em poder passar mais tempo com o filho, situação que não acontecia na vida de ambos (mãe e filho). No seu discurso atual diz "não ver a hora de chegar em casa para brincar com o filho e enchê-lo de beijos". Tal sentimento não era manifestado anteriormente, pois ela não sentia a necessidade de ter um tempo para o filho, possivelmente, pelo efeito da falta de resposta de $\mathrm{C}$. às suas iniciativas de estar com ele.

A participação do pai também evoluiu, pois a mãe passou a relatar que o marido estava passando mais tempo brincando e conversando com o filho. A mudança deles foi sentida tanto pela mãe quanto pelo pai, que afirmaram "não imaginar que nunca tinham brincado realmente com o filho". O tempo que o pai estava em casa era aproveitado despreocupadamente com o filho, inventando jogos de esconder, histórias feitas em desenhos, entre outros. Essas situações eram relatadas pela mãe com bastante orgulho e surpresa, comentando que "na verdade eles pareciam estar conhecendo a si mesmos através do brincar".

Hoje, C. faz suas escolhas sem esperar pela oferta e inicia seu brincar simbólico, dialoga mais durante a brincadeira e busca incluir o outro na mesma. $\mathrm{O}$ trabalho da terapeuta junto à mãe foi investir no brincar e no ouvir C., o que possibilitou deslocamentos importantes para o acesso ao simbolismo, em especial, à capacidade representacional, sobretudo, a falada. Pode-se dizer que isso foi possível por essa disposição dos pais em ouvir e brincar mais com o filho.

Na figura 1, exemplificam-se, com dois recortes do diálogo mãe-filho, transcritos ortograficamente, a evolução de $\mathrm{C}$.

\section{Sujeito 2 (L)}

L., gênero masculino, tinha idade de 4 anos e 2 meses, quando compareceu ao Serviço de Atendimento Fonoaudiológico; foi encaminhado por neurologista e apresentou queixa de atraso na fala. Tinha sido atendido por uma psicopedagoga (educadora especial) por meio da avaliação do Perfil Psicoeducacional Revisado/ (PEP-R).

Segundo a mãe, não houve planejamento da gravidez, tendo a notícia causado certo "susto" ao casal, mas, posteriormente, a novidade foi aceita com grande alegria. A mãe citou que necessitou de 


\begin{tabular}{|c|c|c|c|c|}
\hline № & $\begin{array}{c}\text { Sigla } \\
\text { Locutor }\end{array}$ & Transcrição ao início da terapia & $\begin{array}{c}\text { Sigla } \\
\text { Locutor }\end{array}$ & $\begin{array}{c}\text { Transcrição após } 8 \text { meses } \\
\text { de terapia }\end{array}$ \\
\hline 1 & Mãe-C & $\begin{array}{l}\text {-Olha aqui! Quero ver se tu conhece } \\
\text { essa letra, ó! C., ó! }\end{array}$ & Mãe-C & -C! Posso ver a borboleta? \\
\hline 2 & C & (observa a mãe Ihe mostrando a letra) & C & $\begin{array}{l}\text {-Mamama ( segura a figura e a leva } \\
\text { para mãe ver) }\end{array}$ \\
\hline 3 & Mãe-C & $\begin{array}{l}\text {-Então me diz que cor é essa aqui? } \\
\text { Que cor é essa aqui? }\end{array}$ & $\mathrm{T}$ & -Vai voar lá pra mãe né?! \\
\hline 4 & $\mathrm{C}$ & $-O$ "C". & Mãe-C & -Vem aqui na minha mãozinha. \\
\hline 5 & Mãe-C & $\begin{array}{l}\text {-O "C"! E a cor do "C" qual é? Qual é } \\
\text { a cor do "C"? }\end{array}$ & Pai-C & $\begin{array}{l}\text {-Oh! Um Pokemon aqui na flor ta. } \\
\text { (pai sentado na mesa desenhando) }\end{array}$ \\
\hline 6 & C & $-\mathrm{O}$ "C". & C & $\begin{array}{l}\text { Humm. Parece que é uma bola.(olha a } \\
\text { cartinha que é redonda e que tem } \\
\text { uma borboleta dentro) }\end{array}$ \\
\hline 7 & Mãe-C & $\begin{array}{l}\text {-Que cor, é igual a qual? Que cor é } \\
\text { essa? }\end{array}$ & Mãe-C & $\begin{array}{l}\text { Parece uma bola porque ela tá dentro } \\
\text { de uma bola }\end{array}$ \\
\hline 8 & C & -“C”. & $\mathrm{C}$ & ...ela tá dentro de uma bola \\
\hline 9 & $T$ & -“C", e que cor ela é? & Mãe-C & $\begin{array}{l}\text {-É...que linda! Olha aqui oh. } \\
\text { - Filho...e tá dentro de uma flor } \\
\text { também. Parece... Olha prá borboleta! } \\
\text { (ao longe tenta participar). }\end{array}$ \\
\hline 9 & C & -.... (fala ininteligível) & C & $\begin{array}{l}\text {-Uhmm...não, não é borboleta. Tá bom } \\
\text { a borboleta. }\end{array}$ \\
\hline 10 & $T$ & -É mesmo! É o "C" de C. & Mãe-C & $-A h m !$ \\
\hline 11 & Mãe-C & -Vem cá filho! Ó. Vem cá, ó. & $\mathrm{C}$ & -Hein, sabe o que é boboleta? \\
\hline 12 & & & Mãe-C & $\begin{array}{l}\text { Tava até com saudade desse posto. } \\
\text { (mãe falando sobre o brinquedo). }\end{array}$ \\
\hline 13 & & & $\mathrm{C}$ & $\begin{array}{l}\text {-Sabe? } \\
\text { (em direção da mãe que montava o } \\
\text { postinho) }\end{array}$ \\
\hline 14 & & & $T$ & $\begin{array}{l}\text {-Eu sei o que que é uma borboleta. Tu } \\
\text { sabe? }\end{array}$ \\
\hline 15 & & & Mãe-C & $\begin{array}{l}\text {-Ihh! Que que uma borboleta faz? Ela } \\
\text { voa? } \\
\text { (olha pra C. mostrando que a } \\
\text { terapeuta perguntou e auxilia no } \\
\text { diálogo) }\end{array}$ \\
\hline 16 & & & C & -Voando! \\
\hline 17 & & & Mãe-C & -É! \\
\hline 18 & & & C & -Papai olha! (encaminha-se até o pai) \\
\hline 19 & & & Pai-C & -Deixa eu vver! \\
\hline 20 & & & $\mathrm{C}$ & -A boboleta! (entrega a figura ao pai) \\
\hline
\end{tabular}

Figura 1 - Interação da díade mãe-criança antes e depois da terapia do sujeito 1 (C)

cuidados e repouso durante a gestação por ocorrência de sangramento durante os primeiros cinco meses. O nascimento foi a termo e o parto cesariana e sem intercorrência negativa. No sétimo dia, L. retornou ao hospital com quadro de icterícia, sendo realizado procedimento de fototerapia.
Em relação ao desenvolvimento psicomotor, L. adquiriu o controle cefálico e de tronco, bem como o engatinhar e o andar nos tempos esperados para a idade. Iniciou a fala próximo do quinto mês, e as primeiras palavras ao oitavo mês. Com aproximadamente um ano, houve interrupção da fala, o 
que, segundo a mãe, aconteceu no mesmo período em que o pai esteve mais ausente, em função do trabalho.

L. iniciou escolarização (maternal) com um ano e oito meses, quando voltou a falar palavras soltas, parando, novamente, aos dois anos e seis meses.

Atualmente, a comunicação ocorre preferencialmente na forma gestual, com fala jargonada, oscilando em períodos de maior produção e períodos de ausência. Produz palavras soltas interpretadas pela mãe, mas ininteligíveis para outras pessoas.

Sobre o brincar, foram referidas, na entrevista inicial, manipulação de forma repetitiva e fixação por objetos que rodeiam (ventilador e rodas de carrinhos). Segundo a mãe, L. apresentava humor instável, situações de agressividade (auto e heteroagressão), sobretudo, no ambiente escolar. Também, demonstrava dificuldades em permanecer na mesma atividade e compreendia somente ordens simples, sendo, inclusive, seletivo quanto às informações.

\section{As entrevistas continuadas com os pais de $\mathrm{L}$.}

Ao início dos encontros, o relato da mãe de $\mathrm{L}$. já informava sobre como o comportamento do filho, as suas investidas, causava-lhe estranhamento. Relatou sobre todo o caminho que já tinha percorrido com outros profissionais, até chegar ao serviço para participar deste projeto terapêutico. Foram várias as sessões em que demonstrou revolta, principalmente, sobre a forma como o diagnóstico foi feito e em relação à abordagem terapêutica anterior, em que foi orientada a utilizar reforço negativo quando C. não respondia "adequadamente". Como relatado no caso 1 , a idéia de participar de uma terapia brincando com seu filho foi a situação que mais lhe causou dúvidas, pois havia uma diferença radical entre as duas abordagens.

Mãe-L participava em todos os momentos, questionando muito o "simplesmente brincar". Demonstrou certa desconfiança a respeito da nossa proposta terapêutica: - "Por que é que eu vou perder meu tempo em estar ali só para brincar? Fono tem que fazer falar. Brincar ele faz na escolinha e em casa."

Já nas primeiras entrevistas continuadas, a mãe de L. pareceu bastante à vontade em relatar as situações que experimentara até então em busca de esclarecimentos. Para ela, as entrevistas funcionavam como "um momento para o cafezinho". Sempre demonstrava dúvidas e inquietação ao pensar em como desempenhava atividades em casa com L., pensando em como ela aproveitava os seus momentos de lazer com o filho e o marido. Percebia que o seu envolvimento com o filho era superficial e que não o envolvia nas suas tarefas, pois achava que o mesmo não a compreendia. $\mathrm{O}$ que sabia sobre o "filho autista" dizia respeito ao que ela não poderia investir, pois ele não conseguiria e não teria capacidade para realizar nada como "crianças normais" realizam. Essas constatações causavam irritação na mãe, que relembrava a a experiência anterior de tratamento com o filho.

Reclamava, também, e várias vezes, sobre a postura mantida pelo marido em relação ao filho, pois, em alguns momentos, achava que ela exercia a função materna e paterna sozinha. Considerava que o marido não conseguia participar mais com o filho por não ter tido um modelo, pois teve uma infância difícil e realmente não agia em busca do filho para brincar. Quando o fazia, eram momentos rápidos, sem contato e/ou carinho.

A cada encontro com essa mãe, ocorria um bombardeio de perguntas sobre a síndrome autística: os estudos, a "cura" e os procedimentos de terapia convencionais. Desde o início de sua "peregrinação", termo utilizado por ela, afirmou que passava grande parte do tempo livre buscando informação na internet sobre o tema. Mãe-L fez amizades virtuais com outras mães e mantinha contato na tentativa de obter respostas para o que buscava. Relatou que, em nenhum momento, ouvira de outras mães sobre terapias com o brincar, o que Ihe causava maior desconfiança sobre a terapia proposta por nós.

Felizmente, as entrevistas e as situações vividas, em sessão, passaram a ser mais bem entendidas pela mãe que, em alguns episódios, tomava a sessão para fazer comentários, perguntas, esquecendo-se que o espaço era destinado ao filho. Muitas situações começaram a ser discutidas, sobretudo, as em que o filho se aproximava mais da mãe. Mãe-L entendia que precisava, ao menos, demonstrar ao filho interesse pelo que ele estava querendo dizer e, assim, a atenção do mesmo aumentava em busca da mãe, pois ouvia, era ouvido e iniciava um se fazer ouvir (20).

Falou-se sobre uso da voz como exemplo de que L. podia entender o que pudesse ser explicado com delicadeza e respeito, e que o uso do "não" e "gritos", sugestões da terapia anterior, poderia ser um potencializador do comportamento negativo do filho. O prazer demonstrado na fala da terapeuta, usado como modelo, enfatizava a importância dessa fala na projeção sobre o brincar, atribuindo sentido às ações de $\mathrm{L}$.

A integração do pai para esse novo olhar sobre L. era referida (pela mãe) como de forma lenta. Um cansaço diário (do trabalho) aparecia como desculpas para não brincar com o filho. Na maioria das entrevistas, o assunto do brincar era retomado, principalmente, quando o pai acompanhava a mãe, 
o que passou a acontecer com maior freqüência, após quatro encontros realizados somente com a mãe. Os relatos da mãe sobre as tentativas do pai eram seguidos de muito riso, pois dizia que 0 marido "funcionava 48 horas" e depois tudo voltava como antes.

Nas palavras da mãe, hoje L. é outra criança e ela se tornou uma mãe que se sente acreditando a cada instante que o filho tem capacidade para desenvolver-se saudavelmente em um ambiente em que se" brinca longe dos dvd's".

\section{Reflexos das entrevistas na interação com $L$.}

O processo terapêutico iniciado com L. foi semeIhante ao desenvolvido no caso do sujeito 1 (C), sendo inicialmente trabalhado o resgate do vínculo materno por meio das sessões de terapia conjunta (mãe, o sujeito e a terapeuta) e das entrevistas continuadas.

O reflexo das entrevistas no comportamento familiar do sujeito $2(L)$ foi bastante positivo e o brincar dos pais com L. se tornava, a cada dia, mais efetivo. A mãe passou a brincar com maior naturalidade e entrega. $O$ brincar da mãe acarretava o envolvimento de $L$. na brincadeira e na sua maior aproximação com ela. A mãe contava tal constatação com alegria, pois não imaginava que com "isso, fazendo isso, tudo mudaria". L. já brincava de carrinho sem ficar rodando exclusivamente as rodas; criava brincadeiras; entendia o brincar de esconder; ajudava a mãe em tarefas domésticas quando convidado e os ambientes cheios não o incomodavam mais. De certa forma, a rotina da família parecia sofrer um efeito normalizador. A convivência de L. com os colegas melhorou, tanto pelos reflexos da terapia, como pela boa acolhida e manejo da escola em relação às dificuldades de $L$.

$O$ relato da mãe sobre essa evolução surpreendia-nos, pois dizia que "pela primeira vez, sabia o que era sentir o carinho do filho". Toda essa descoberta de afeto, busca e desejos eram relacionados ao fortalecimento do vínculo materno e ao aprender a brincar. O discurso da mãe deu-nos, portanto pistas claras de sua descoberta e do seu aprendizado ("aprendi a brincar"). Esse progresso, com freqüência, era informado à terapeuta que recebia mensagens via celular, contando alguma situação sobre o desenvolvimento de L. Um, de tantos, foi o relato de uma frase do filho antes de dormir que dizia: "eu te amo mamãe". Esta expressão passou a correr rotineiramente.

No final da pesquisa, o medo, a incerteza e a ansiedade manifestados pelo casal e, principalmente, pela mãe, estavam quase ausentes. A satisfação com a vida familiar e social de L. refletia 0 trabalho desenvolvido nas entrevistas continuadas, as quais davam oportunidade da mãe falar e, em meio aos sentimentos mais dolorosos, dela resgatar o filho imaginado. Na figura 2, são exemplificadas interações antes e de depois da terapia

\section{Sujeito 3 (A)}

A., também do gênero masculino, com idade inicial de 2 anos e 1 mês, foi encaminhado ao setor de linguagem com queixa da família e da escola de ausência de fala e restrito comportamento social.

O histórico gestacional foi acompanhado por situações de estado emocional conturbado e ocorrência de períodos de negação da gravidez, não planejada, pelo casal. O parto foi a termo, embora tenha sido realizado um parto cesariano de urgência, sendo o bebê encaminhado diretamente para o oxigênio e permaneceu em incubadora por 24 horas. Teve icterícia neonatal e realizou fototerapia por, aproximadamente, quatro dias.

Sobre o desenvolvimento neuropsicomotor, iniciou marcha, com apoio, próximo dos 10 meses e marcha, sem apoio, com 1 ano e 3 meses. A mãe referiu não observar a emissão de nenhuma palavra (com significado) ou com função comunicativa até o momento da entrevista.

\section{As entrevistas continuadas com os pais de $A$.}

O trabalho com a mãe de $A$, diferenciou-se dos realizados com as outras mães, visto que ela apresentava uma condição emocional agravada em relação a si e ao ambiente familiar (crise conjugal). Sempre estava bastante angustiada e relatava sentimento de culpa pela situação do filho. Não entendia o que acontecia, parecendo ser sugada para um ambiente de extremo desconhecimento e conflito.

Nos primeiros encontros, com frequência quinzenal, a mãe questionava muito o motivo do filho não falar - "Por que ele não fala?"- parecendo esperar que a terapeuta respondesse a todas as suas dúvidas, esperando que uma "receita" fosse prescrita para o tratamento do filho. Desconversava quando o assunto se encaminhava para os seus desejos e suas vivências. A condução das entrevistas foi mudando de direcionamento quando conseguiu chorar demonstrando sua fragilidade, situações de angústia, medo e insatisfação na sua vida conjugal e na convivência com familiares do marido. Comentou sobre situações que ocorriam no ambiente familiar em que ela sentia-se "presa, sufocada", demonstrando necessidade em falar, "pôr para fora a dor que sentia". Porém, até chegar neste estado, a mãe apresentou certa resistência, querendo desconversar, principalmente, sobre os assuntos relacionados à sua infância e à imagem que tinha de sua própria mãe; tentava organizar seu discurso de forma a demonstrar domínio sobre si, 


\begin{tabular}{|c|c|c|c|c|}
\hline № & $\begin{array}{c}\text { Sigla } \\
\text { Locutor }\end{array}$ & Transcrição ao início da terapia & $\begin{array}{c}\text { Sigla } \\
\text { Locutor }\end{array}$ & $\begin{array}{c}\text { Transcrição após } 10 \text { meses } \\
\text { de terapia }\end{array}$ \\
\hline 1 & Mãe-L & -Olha aqui, vamos mostrar pra tia M. & $\mathrm{L}$ & $-\mathrm{O}$ que tem ali? \\
\hline 2 & Mãe-L & $\begin{array}{l}\text {-L, a tia M não sabe. Que letra que é } \\
\text { essa aqui ó, ó? }\end{array}$ & Mãe-L & -A mamãe não quer mais comer. \\
\hline 3 & $\mathrm{~L}$ & $\begin{array}{l}\text {-L } \\
\text { (continua a rabiscar o quadro com o } \\
\text { giz, parecendo não prestar atenção. } \\
\text { Em seguida, L vai até a mesa pegar } \\
\text { um giz.) }\end{array}$ & $\mathrm{T}$ & $\begin{array}{l}\text { (Risos). } \\
\text {-Tomou café já mãe? }\end{array}$ \\
\hline 4 & Pai-L & - Ó o azul. & Mãe-L & $\begin{array}{l}\text { (Risos). } \\
\text { - Mamãe já tomou café }\end{array}$ \\
\hline 5 & Mãe-L & - Que letra que é essa aqui? & $\mathrm{L}$ & -Não! \\
\hline 6 & Mãe-L & $-\mathrm{L}$. & Mãe-L & A não? Quer mais uma coisinha? \\
\hline 7 & L & $\begin{array}{l}\text {-L } \\
\text { (faz mais algumas garatujas e repete } \\
\text { o que a mãe disse se aproximando da } \\
\text { letra por ela escrita.) }\end{array}$ & $L$ & ...bolacha! \\
\hline 8 & $\mathrm{~L}$ & -L. & Mãe-L & -Tem bolacha aqui? \\
\hline 9 & $\mathrm{~L}$ & $-U$. & & (Mãe e filho procuram algo no cesto.) \\
\hline 10 & $T$ & -Tu sabe a letra do teu nome então. & Mãe-L & $\begin{array}{l}\text {-Tem nada! A Michele não foi no } \\
\text { mercado. }\end{array}$ \\
\hline 11 & Mãe-L & -E esse aqui? & $T$ & O mercado tava fechado! \\
\hline 12 & L & $-\mathrm{C}$ & L & $\begin{array}{l}\text {-... mãe. Esse aqui mãe. (mostra } \\
\text { brinquedo) }\end{array}$ \\
\hline 13 & Mãe-L & $-\mathrm{OC}$ & & \\
\hline 14 & Mãe-L & -E esse aqui? & Mãe-L & -Esse aqui? \\
\hline 15 & $L$ & $-\ln$ & $L$ & pega brinquedos e organiza no chão. \\
\hline 16 & Mãe-L & -E esse aqui? & Mãe-L & $\begin{array}{l}\text { Bota no fogão. Esse aqui ó. Fazer } \\
\text { comida aqui ó (coloca panela no } \\
\text { fogão) }\end{array}$ \\
\hline 17 & L & $\begin{array}{l}- \text { O. } \\
\text { (A cada letra que a mãe escreve e ele } \\
\text { nomeia, em seguida risca a mesma. ) }\end{array}$ & $\mathrm{L}:$ & $\begin{array}{l}\text { Não. (retira a panela do fogão e } \\
\text { coloca com os outros brinquedos que } \\
\text { está arrumando) }\end{array}$ \\
\hline 18 & Mãe-L & $\begin{array}{l}\text {-Tudo junto fica? } \\
\text { (Faz um risco abaixo do nome. A } \\
\text { criança também faz um risco abaixo } \\
\text { da escrita e depois a mãe mais uma } \\
\text { vez sublinha o nome que escreveu. ) }\end{array}$ & Mãe-L & -Mas. \\
\hline 19 & Mãe-L & $\begin{array}{l}\text {-Como é que fica tudo junto? } \\
\text { (O menino se afasta, indo até a mesa } \\
\text { e ficando de costas para a mãe. } \\
\text { Responde, mas errado. ) }\end{array}$ & $L$ & -No chão. \\
\hline 20 & Mãe-L & Não. Fica L. & Mãe-L & -No chão? Então, tá! \\
\hline 21 & & & L: & -Aqui \\
\hline 22 & & & Mãe-L & $\begin{array}{l}\text {-Ahh, tu achou oh... Olha aqui, uma } \\
\text { colher rosa. (mexe na panelinha com } \\
\text { a colher) }\end{array}$ \\
\hline 23 & & & $L$ & $\begin{array}{l}\text { (imita a mãe mexendo com colher no } \\
\text { prato.) }\end{array}$ \\
\hline 24 & & & Mãe-L & - Qué um pouquinho? \\
\hline 25 & & & $\mathrm{~L}$ & Tô sem fome. \\
\hline
\end{tabular}

Figura 2 - Interação da díade mãe-criança antes e depois da terapia no sujeito 2 (L) 
excluindo seus sentimentos como possíveis geradores das dificuldades que enfrentava ao agir com o filho.

O foco inicial das entrevistas era a condição e o tratamento da criança frente às dificuldades de interação com o Outro, pois afirmava o desinteresse do filho nas situações diárias. O choque vivido por essa mãe durante o período gestacional foi gradativamente sendo informado, dando-se elementos para que ela refletisse sobre seu papel (materno) e sobre o fato de tê-lo deixado vago para a sogra e cunhada. A partir daí, as sessões de entrevistas aumentaram para uma frequência semanal.

Seus relatos informavam que não lembrava de ter sentido a satisfação e a felicidade em ser mãe (por não ter sido uma gravidez planejada); dizia ter recebido apoio do marido ("ele foi ótimo, o melhor possível durante a gravidez"), com cuidados e carinho. Depois do nascimento de A., sentiu-se esquecida, deixada de lado, fazendo a seguinte colocação: "agora já nasceu, não sirvo mais". Para a mãe ninguém mais se preocupava em como ela estava se sentindo, todas as atenções eram dirigidas ao bebê e agora, ela "só servia para alimentar o filho".

Após o parto, Mãe-A relatou não querer voltar para casa. Queria ficar no hospital "para sempre" não querendo ver o filho. Não entendia o que estava acontecendo e, nesse momento, deixou que a sogra e a cunhada assumissem o seu papel de mãe. Esse fato ficou evidente na entrevista inicial, pois quem informava a respeito das perguntas realizadas na triagem sobre o desenvolvimento de $A$. era a cunhada que acompanhava o casal. A fonoaudióloga responsável pela triagem, percebendo o fato, direcionou perguntas para a mãe que disse que a gravidez "foi o pior momento da minha vida", na frente de todos. A estratégia, então, foi acolhêla incondicionalmente e valorizar a sua participação na terapia e na vida do filho.

A partir do vínculo estabelecido com a terapeuta, buscou-se discutir elementos da terapia de A. e alternativas para melhorar a relação da mãe com ele. Foram discutidos seus comportamentos diretivos e o quanto eles causavam o retraimento de A., pois a mãe, como será visto na sequência dialógica antes da terapia, tentava manipular o corpo do filho para que ele respondesse a ela.

Nas conversas sobre como as terapias ocorriam, a mãe passou a comentar que percebia sua dificuldade em entregar-se ao filho e o sentimento de culpa por ter deixado seu espaço ser preenchido por outros; entendeu que tais fatos atrapalhavam a sua aproximação com o filho. Percebeu que necessitava assumir seu papel de mãe, mas projetava para o marido parte de sua dificuldade, pois este se concentrava muito em sua família de origem.
Aparentemente, passou a demonstrar maior serenidade para abordar a situação do filho. Não entendia por que A. "parou de ser como era". Referiu que antes ele olhava mais, interagia e parecia querer falar (chorou). Sentia-se culpada por ele "estar daquele jeito".

A percepção das dificuldades colocadas pela mãe fez com que houvesse a necessidade de supervisão de uma psicóloga para a efetivação das orientações. Iniciou-se, então, um processo de conscientização da mãe acerca de ela mesma ter um espaço para si, ou seja, de iniciar atendimento psicológico, visto que cabia à fonaudióloga retomar o foco das conversas sobre a terapia do filho e sua participação nelas. Foi explicada para a mãe a necessidade de continuar as entrevistas sobre o vivido em terapia e, a partir das colocações realizadas, iniciou-se trabalho psicológico individual com a mãe e, posteriormente, com o pai na busca de se reestruturar o ambiente familiar. No entanto, embora a mãe tenha apresentado tão forte demanda pela a mesma, ela não a frequentava com a mesma assiduidade do pai. O estado emocional da mãe apresentou picos e disfunções preocupantes como bulimia nervosa, emagrecimento e crises depressivas. Um fato interessante relatado pela mãe nesse período foi a busca de A. por ela, procurando abraçá-la nas costas e na cabeça, parecendo, aos olhos da mãe, que o filho queria protegê-la. Mesmo com os atendimentos psicológicos para a mãe, esta ainda demandava muita atenção no espaço terapêutico do filho, sendo necessário alertá-la para a necessidade de trabalhar determinados assuntos com a sua terapeuta. Contudo, Mãe-A procurava maior envolvimento nas sessões com o filho e relatava sentir diferenças na forma como vinha brincando, percebendo mudanças no olhar e sorriso do filho.

Portanto, a partir do espaço de terapia psicológica aberto para a mãe, foi possível voltar às entrevistas continuadas sobre $A$. para uma frequência quinzenal. A mãe passou a demonstrar o desejo de ser mãe, e a se esforçar para entregar-se ao filho e ao brincar. O esforço em organizar a sua família ocorreu, inicialmente, sem o apoio do marido e, ao final da pesquisa, com uma maior união do casal.

A desarmonia vivida no ambiente familiar causava grande variação no comportamento dos três envolvidos, dificultando a evolução de A., que se mostrava menos presente na terapia.

Em meio a esse processo, os pais começaram a desejar um parecer biológico das condições de A., foram, então encaminhados para uma avaliação neurológica na clínica-escola e depois encaminhados para o serviço de neurologia do hospital institucional para realizar exames. Ao serem atendidos no hospital, o neurologista colocou um quadro 
excessivamente pessimista em relação a A., o que gerou crise e descontentamento da família com as informações que até o momento tinham sido fornecidas em terapia e em investigação pelo neurologista da clínica-escola.

Realizou-se uma entrevista com o casal e a orientadora desta pesquisa e trabalho, na qual se explicou a posição de A. no espectro autístico. Falou-se da gravidade atual do caso e das possíveis implicações orgânicas e psíquicas familiares que incidiam sobre A., pois se descobriu que toda a família (materna e paterna), inclusive o casal, sofria de distúrbios psiquiátricos (bipolaridade, depressão, crise de pânico, entre outros). Buscouse demonstrar que mesmo que $A$. tivesse uma predisposição orgânica para o autismo, ele também tinha um ambiente familiar que não estava bem até o momento. Na ocasião, o casal, lembrou-se de situações do primeiro ano de vida de A. demonstrando, pelo relato, que o menino esboçava características do terceiro tempo do circuito pulsional, mas que elas haviam sumido depois de o pai passar três dias pescando (primeiro ano de vida). Esse relato causou a impressão de que $A$. apresentou um retraimento maior quando a figura mais presente no dia-a-dia, o pai, ausentou-se por um período prolongado. Explicaram-se as possíveis consequências disso, sem muitos detalhes para não alimentar o sentimento de culpa do casal que já era grande.

Nessa última entrevista, foram traçados objetivos a partir das evoluções de A. e possibilidades para abrir espaços de relacionamento. O casal voltou a perceber as evoluções e a investir na relação com o filho após a entrevista, pois, também, foi deixado claro que muitos dos impedimentos eram de A. Ou seja, buscou-se demonstrar que, seja pela via da herança genética, ou pela questão de relacionamento familiar, que eles não deviam ficar culpandose pelo ocorrido, pois desenvolvimento psíquico se trata de algo sobre o que não se tem total controle. A única possibilidade que se tinha era investir no que podia ser positivo, descobrindo as potencialidades de A. Deixou-se claro que isso ocorre com quaisquer pais, e por isso, reiterou-se a importância deles manterem seus espaços terapêuticos individuais.

\section{Reflexos das entrevistas na interação com A.}

Ao início dos atendimentos, na maioria das situações, A. não demonstrava simbolismo e/ ou contato visual. Corria muito de um lado para o outro, batendo com as mãos onde parava. Parecia demonstrar desconforto e ansiedade (tremores, pressão no fechamento mandibular, intensos jargões e mímica facial de choro). Não demonstrava interesse às investidas da mãe.
As conversas nas entrevistas continuadas sobre a ansiedade da mãe, percebidas nas sessões conjuntas, permitiram que a mãe fosse reorganizando sua ação e esperasse mais as respostas de A. A mãe foi observando que, em alguns momentos, quando seu ato não se tornava extremamente dirigido, a criança ensaiava um brincar exploratório, mas logo abandonava pela intrusividade materna, em função de muitas perguntas e comandos. Deste modo, acabava dispersando a atenção de A. e aumentando seu retraimento.

Nas sessões de A., as tentativas da mãe em participar do movimento da criança não apresentavam retorno, embora o seu esforço ocorresse em muitos momentos. Eram raras as ocasiões em que a mãe conseguia trazer o olhar do filho para o que realizava. Uma ação em que a criança fixava sua atenção na mãe era quando, em sussurros, ela Ihe contava alguma situação ou tentava interpretar algum jargão emitido pelo filho.

Nas entrevistas, os momentos de retorno de A. eram vistos com muita alegria pela mãe. Por isso, modificou-se a atitude de buscá-lo pela proposição de brincadeiras com o carro ou a bola, para interpretar, com fala em manhês ${ }^{13}$, sua exploração sensório-motora. Com essa nova abordagem, as falas da terapeuta e da mãe se constituíram em uma ponte entre a conduta sensório-motora e o simbolismo em que se ancora o ouvir de A., abrindo, ao mesmo tempo, espaço para que ele seja ouvido.

Iniciou-se então uma ampliação da compreensão da linguagem de A. e um certo retorno à proposição da mãe de brincarem. É importante ressaltar que, quando a mãe estava tranquila e focada no filho, o não retraimento do menino ocorria e sua aceitação da brincadeira era maior. A. começava a se engajar em brincadeiras com o uso convencional de objetos, evoluindo de sua exploração sensório-motora. Esse fato parece se relacionar à maior disponibilidade dessa mãe em ouvir e em tentar interpretar o funcionamento do filho, que demonstrava maior contato manifestando-se com o olhar em busca do Outro.

Do mesmo modo, o pai, quando acompanhava as entrevistas ou até realizava entrevistas individuais com a terapeuta, parecia perceber com maior tranquilidade o progresso de A. Percebeu-se na saída, de algumas sessões, que A. já esboça suas primeiras palavras presas ao contexto "mamã" (quando vê a mãe) e "tatu" (apelido do pai). Ele passou a responder mais quando chamado, tanto pelos pais como pela terapeuta e orientadora deste trabalho. Estava mais concentrado e as estereotipias estavam diminuindo. Alguns exemplos da dialogia antes e depois da terapia estão expostos na figura 3. 


\begin{tabular}{|c|c|c|c|c|}
\hline № & $\begin{array}{c}\text { Sigla } \\
\text { Locutor }\end{array}$ & Transcrição ao início da terapia & $\begin{array}{l}\text { Sigla } \\
\text { Locutor }\end{array}$ & $\begin{array}{l}\text { Transcrição após } 12 \text { meses } \\
\text { de terapia }\end{array}$ \\
\hline 1 & Mãe-A & Olha ali a bolha! Olha ali a bolha A. & $A$ & $\begin{array}{l}\text { (puxa uma das cadeiras da mesa } \\
\text { pequena) }\end{array}$ \\
\hline 2 & $A$ & Tatuiii. & Mãe-A & $\begin{array}{l}\text { Vai sentar na cadeirinha? A cadeirinha } \\
\text { é só pra sentar, tá! }\end{array}$ \\
\hline 3 & & $\begin{array}{l}\text { Mãe-A: Olha ali A. atrás de ti, olha lá } \\
\text { tem outra. Outra ali A. }\end{array}$ & $A$ & $\begin{array}{l}\text { (olha para a mãe e balança a cabeça } \\
\text { afirmativamente) }\end{array}$ \\
\hline 4 & A & $\begin{array}{l}\text { Hummm, atuim. - Parece irritado, } \\
\text { anda pela sala. }\end{array}$ & Mãe-A & $\begin{array}{l}\text { Se tu vai sentar, a mamãe também } \\
\text { senta. }\end{array}$ \\
\hline 5 & $\mathrm{~T}$ & Tu quér ir embora? É isso? & A & (encosta-se na cadeira) \\
\hline 6 & $A$ & $\begin{array}{l}\text { intensifica jargões, parecendo } \\
\text { manifestar negação, irritabilidade. }\end{array}$ & Mãe-A & $\begin{array}{l}\text { Senta aí, que a mamãe senta aqui! } \\
\text { Senta! Senta! }\end{array}$ \\
\hline 7 & Mãe-A & $\begin{array}{l}\text { Vamos escrever. Olha aqui ó...olha } \\
\text { aqui ó. }\end{array}$ & $A$ & (balançar afirmativo de cabeça) \\
\hline 8 & A & Auiiii, tatuuumm & Mãe-A & $\begin{array}{l}\text { Senta! Vamos sentar que eu vou fazer } \\
\text { umas bolhazinha (risos). }\end{array}$ \\
\hline 9 & $\mathrm{~T}$ & $\begin{array}{l}\text { Então vamos dar uma olhada ali nas } \\
\text { coisas ali fora? }\end{array}$ & $A$ & $\begin{array}{l}\text { (debruça-se sobre a mesa e sorri para } \\
\text { a mãe quando esta faz bolhas. Olha } \\
\text { para as bolhas e sorri) }\end{array}$ \\
\hline 10 & Mãe-A & Quer escrever? & & \\
\hline
\end{tabular}

Figura 3 - Interação da díade mãe-criança antes e depois da terapia do sujeito 3

\section{RESULTADOS}

Ao início dos atendimentos, o enfoque terapêutico dado aos três casos buscava aproximar mãe e filho, de forma a incrementar o vínculo mãe-filho, bem como as possibilidades de a mãe interpretar as manifestações comunicativas do filho. Esse resgate relacional era esclarecido nas entrevistas continuadas com as mães sempre fazendo relação com aspectos vividos em terapia, que passaram a ser melhor compreendidos por elas, em distintos momentos do processo terapêutico. Assim, questões sobre o vínculo materno (em estabelecimento) e o papel do brincar foram amplamente discutidas e relatados durante as entrevistas continuadas como processo modificador na forma dessas mães e pais comportarem-se diante dos filhos.

Os primeiros encontros, foram reservados à escuta familiar com o objetivo de auxiliar os pais e, principalmente, orientá-los sobre a necessidade do espaço terapêutico para o seu filho. Num primeiro momento, nos casos do sujeito $1(\mathrm{~L})$ e do sujeito 2 (C), as mães se fizeram mais presentes e no caso do sujeito $3(A)$, embora o pai comparecesse às sessões, a mãe se manifestava mais. Tal estratégia terapêutica foi usada considerando o relato inicial dos pais, o qual demonstrava grande angústia e necessidade em falar sobre seus sofrimentos frente às expectativas frustradas quanto ao desenvolvimento de seus filhos; investiu-se, pois, mais nas entrevistas das mães, para se refletir sobre a situação vivida pelas mesmas e, assim, tentar construir novos caminhos de investimento no filho.

Com o espaço disponibilizado para os pais relatarem suas dúvidas e angústias em relação as suas limitações sobre o investimento "correto" aos filhos, o resultado do procedimento terapêutico com objetivo de auxílio e esclarecimento nas entrevistas continuadas foi positivo, pois, a partir do envolvimento dos mesmos com o brincar, as sessões passaram a ocorrer com menor dificuldade, tendo as mães maior disponibilidade em participar daquele momento com seu filho de forma espontânea e menos questionadora. Ao mesmo tempo, as sessões conjuntas entre mãe e filho passaram a enfatizar a interação com o filho, já que anteriormente, em vários momentos, principalmente com a mãe do sujeito $3(A)$, o espaço da terapia do filho era tomado pelas mães em função de seu sofrimento o que demonstrou a necessidade de esta mãe buscar um espaço terapêutico para si.

O resultado terapêutico com o investimento no brincar simbólico, manifestado pelos sujeitos 1(L) e sujeito $2(C)$, tornou-se suficiente para que as mães, nas sessões conjuntas, encontrassem caminhos de interação com seus filhos e pudessem voltar a ocupar suas funções parentais junto aos seus esposos. Os pais passaram a investir em uma aproximação com os filhos por meio do brincar, retomando a função paterna nos momentos em que ela foi se fazendo necessária. Assim, pode-se identificar, num primeiro momento, uma maior evolução 
no exercício da função materna, pelo comparecimento mais assíduo das mães à terapia. Em um segundo momento, a presença dos pais viabilizou o trabalho com os mesmos em sua possibilidade de brincar com seus filhos. Tais exercícios foram possibilitados pelas sessões e pelas entrevistas continuadas ${ }^{21}$ realizadas com o casal. Sobre o brincar do sujeito $3(\mathrm{~A})$, este ainda encontra-se no brincar sensório-motor, portanto não foi possível iniciar uma perspectiva mais focada no simbolismo durante o brincar através de intervenção propositiva, o que foi modificado no percurso terapêutico através da projeção do manhês ${ }^{15}$, sendo de fundamental importância para que a mãe voltasse a investir na relação com o sujeito, oportunizando uma sustentação, cada vez maior, da interação entre o filho e sua mãe.

No decorrer dos encontros, os pais passaram a participar com maior frequência e, estando as mães mais orientadas sobre o percurso da terapia, o envolvimento dos pais foi gradativamente estabelecendo-se. Estes passaram a respeitar o espaço dedicado ao atendimento do filho, o que era retomado nas entrevistas continuadas para demonstrar a importância do momento adequado para o pronunciamento em sessão. Convém destacar que em alguns encontros, os pais não estavam presentes pela dificuldade em conciliar o horário da sessão com o horário de trabalho.

As três mães apresentaram grande envolvimento nas entrevistas e sessões com os filhos, embora algumas tenham necessitado de maior tempo para assimilar a estratégia com o brincar e, principalmente, perceber que em "seu filho com problema" existia uma criança que, em sua singularidade, precisava ser ouvida.

\section{DISCUSSÃO}

Nos casos estudados foi possível perceber a importância da entrevista continuada não só para realizar possíveis orientações aos familiares do sujeito, como para entender melhor a dinâmica familiar, principalmente a constituição dos casais e o exercício das funções parentais dos mesmos. Essa estratégia, tão comum na clínica psicológica da infância, não é usual na Fonoaudiologia, no entanto, alguns trabalhos já relatam sua importância exatamente como se viu nesta pesquisa ${ }^{11}$.

Percebe-se que havia, nos casos S1 e S2, dificuldades do casal em entregar-se à relação com o filho, que se manifestava em um desconhecimento, e até, em uma resistência ao brincar. No entanto, tal resistência também se devia às orientações em terapia comportamentalista realizadas anteriormente, fato referido pelas mães de
S1 e S2. O mesmo foi observado na mãe de S3. Para esta mãe, no entanto, havia um histórico em relação à dificuldade de ocupar a função materna, relacionado a questões do seu histórico familiar e seu preparo para ser mãe. Também o fato de seu filho possuir um evidente caso de autismo infantil, com possibilidades de retorno às investidas da mãe muito menores do que S1 e S2. Esses resultados colocam em relevo a importância de se observar as condições orgânicas e cognitivas dos sujeitos em conjunto com as condições subjetivas possíveis na sua relação com a figura materna já destacada em alguns estudos ${ }^{10,15}$.

De modos distintos, as três mães demonstraram algum tipo de desistência do filho e de entrega do mesmo aos "DVDs", como relatavam sobre os momentos em que deixavam os filhos em frente à televisão, sobretudo, nos casos S1 e S2. Nesses dois casos, vê-se também o efeito do diagnóstico do autismo que parece ter levado as mães (S1 e S2) a duvidar das possibilidades dos filhos, concentrando-se na doença. Vários estudos referem o estresse pelo qual sofrem os pais de autistas ao receber o diagnóstico e a importância de se dar suporte aos mesmos para lidar com a situação de reajuste às necessidades do filho ${ }^{16}$.

A reconstrução da imagem do filho foi um aspecto muito importante nos casos $\mathrm{S} 1$ e $\mathrm{S} 2$, pois, de modo diferente de S3, os sujeitos C. e L. apresentavam possibilidades de simbolismo já ao início da terapia, o que não os caracterizava como "autistas clássicos". Por isso, o diagnóstico de autismo, com descrição de características clássicas e graves projetada sobre seus filhos pela terapeuta anterior fez com as mães de C. e L. não percebessem as potencialidades de ambos. Com a compreensão progressiva do papel do brincar, houve grande evolução de ambos os sujeitos, e também, uma ocupação progressivamente maior da função materna por elas referidas.

Do mesmo modo, os pais, antes ausentes, passaram a ser mais presentes, sobretudo, o pai de C. que apresentou maior facilidade em se entregar ao brincar com o filho. Como efeito, houve o exercício cada vez maior das funções parentais em ambos os casos. Houve resgate de um plano simbólico para os filhos ${ }^{8,14}$. Ambos deixaram de ser "autistas" de modo que puderam ser reconhecidos em sua singularidade, apesar de tantos diagnósticos e orientações equivocadas.

Já no caso S3 (A), em que possivelmente haja maior comprometimento orgânico do menino (aspectos em investigação), somado às características familiares nada propícias ao desenvolvimento de uma criança, o processo terapêutico de resgate da subjetividade tem sido mais lento. A falta 
de retorno do próprio sujeito pode ter tido efeito importante sobre o comportamento materno (o fato de a mãe ter feito suas investidas e não ter recebido resposta pode ter alimentado sua ausência de função materna). No início da terapia, ficou evidente que a Mãe-A tentava investir e não conseguia retorno, sua ansiedade aumentou muito, o que fez emergir mais conflitos familiares.

Também a desconfiança em relação ao "simplesmente brincar" se fez presente na terapia de A. e, tanto a mãe quanto o pai puderam compreender sua importância. Ressalta-se que ambos tiveram um entendimento imediato disso, pois não haviam recebido orientações contrárias anteriormente, já que esta é a primeira terapia da qual participam de A. e seus pais. No entanto, isso não necessariamente se refletiu em poder sustentar esse brincar imediatamente, em função das dificuldades apresentadas pelo casal e por A.

Com as entrevistas continuadas, esse casal foi, a exemplo dos outros, ocupando mais suas funções parentais, embora tenham limitações pessoais mais significativas. No entanto, os progressos de A. e a diminuição da ansiedade do casal, ancorados tanto nas sessões conjuntas quanto nas entrevistas continuadas, demonstraram que tais recursos terapêuticos são fundamentais na clínica infantil, pois nela está implicado o laço familiar com o sujeito 8,10,14,15.

Como visto na descrição das entrevistas, quando as mães e, posteriormente, os pais desses sujeitos passaram a agir de forma tranqüila, oferecendo-se durante o brincar com os filhos, é que perceberam que de alguma forma "não sabiam brincar". Eles tinham a necessidade em demonstrar que seus filhos detinham conhecimento como nomes de objetos, números e letras.

O espaço de escuta oferecido para essas mães durante as entrevistas continuadas foi um acelerador no processo de entendimento sobre as estratégias terapêuticas. Os momentos que algumas mães tomavam da sessão do filho, buscando desabafar, por exemplo, praticamente desapareceram, ou seja, passaram a ser respeitados por elas, visto que sabiam que a sessão era dos filhos. Eram alertadas sobre o espaço do sujeito e retomavam sua postura de participante na interação, pois sabiam que também teriam o seu espaço e o seu momento.

Pensando nos processos sofridos por cada sujeito e respectiva mãe nesse período de terapia e a oferta de um espaço que possibilite reflexões sobre a relação da díade, fica visível o resgate do vínculo mãe-filho e o investimento no diálogo que foi possível a partir da retomada do gozo materno por meio do brincar, sobretudo, nos casos S1 e S2.

No caso do $\mathrm{S} 3$, a sustentação terapêutica da mãe e do filho demandam esforço maior, já que o sujeito possui alterações estruturais mais importantes e está com dificuldades de se constituir na linguagem. No entanto, os pequenos progressos são sinalizados pela terapeuta aos pais para que percebam que há uma evolução e que é importante ter resiliência e perseverança no investimento interacional.

Embora o investimento dos pais do S1 e do S2 tenha sido menor do que do pai S3, percebe-se que conseguir a presença e participação dos pais foi também fundamental tanto para os sujeitos, como para as mães, pois permitiu que estas se sentissem apoiadas pelo marido no processo terapêutico do filho. Isso também teve efeitos na relação dos casais.

Outro aspecto a ser ressaltado é que houve uma equipe de profissionais (Fonoaudiológico e Psicológico) realizando trabalho transdisciplinar nos três casos, pois a psicóloga e a fonoaudióloga orientadora deste trabalho, juntamente com a terapeuta pesquisadora, discutiram quase que semanalmente a terapia dessas famílias, fosse pela discussão dos conteúdos surgidos nas entrevistas continuadas ou pela observação das sessões dos sujeitos (individuais ou conjuntas com os pais). Esse processo foi fundamental para ancorar esse trabalho transdisciplinar, pois conhecimentos de linguagem, de psicanálise e de desenvolvimento infantil (como um todo) foram fundamentais para os processos fonoaudiológicos aqui relatados.

\section{CONCLUSÃO}

A partir do exposto, é possível concluir que o papel das entrevistas continuadas foi fundamental na participação de mães e pais durante o processo terapêutico fonoaudiológico de seus filhos que apresentam características do espectro autístico.

Permitem que as temáticas surgidas nas sessões conjuntas sejam discutidas e que sejam abordadas as dificuldades dos pais em assumir suas funções e em seguir as orientações terapêuticas. O entendimento da essência dessas dificuldades pode, então, ser remetido para o processo terapêutico individual dos pais, quando necessário.

Os efeitos das entrevistas continuadas no processo terapêutico são visíveis visto que, sem elas, possivelmente não se obtivessem as mudanças nos sentimentos e comportamentos parentais com a qualidade alcançada nos casos estudados. Trata-se, portanto, de um recurso fundamental na clínica fonoaudiológica voltada aos distúrbios da linguagem infantil. 


\section{ABSTRACT}

Background: continued interviews with mothers and fathers of subjects with autistic spectrum on the therapeutic process in speech therapy. Procedures: interviews with the subjects' parents were made bi-weekly during 24 months and we account the content for the after-analysis. Data was analyzed as for the global context of the case. Results: the open room for the continuous interviews was crucial for parents in order to discuss their doubts about the limitations of their children and to reflect on aspects, such as playing, communication and setting limits with their children. They also could think about their on parental function practice. This process was more intense in the group of mothers than in the fathers' group. As an effect there were better conditions in playing and in dialogic interaction among parents and children. Conclusion: the continued interview was perceived as a fundamental aspect of the therapeutic process conducted under the theoretical perspective that includes psychoanalysis and interactive conception of language acquisition.

KEYWORDS: Speech, Language and Hearing Sciences; Interview; Language; Maternal Behavior; Autistic Disorder

\section{REFERÊNCIAS}

1. Barbaresi W J, Katusic S K, \& Voigt R G. Autism: A review of the state of the science for pediatric primary health care clinicians. Archive of Pediatric and Adolescent Medicine. 2006;160: 1167-75.

2. Fombonne E., Zakarian R., Bennett A., Meng L. \& Mclean-Heywood D. Pervasive developmental disorders in Montreal, Quebec, Canada: prevalence and links with immunizations. Pediatrics. 2006; 118: 139-50.

3. Gernsbacher M A, Dawson M, \& Goldsmith H H. Three reasons not to believe in an autism epidemic. Current Directions in Psychological Science. 2005; 14: 55-8.

4. Schechter R, Grether J K. Continuing increases in autism reported to California's Developmental Services System: Mercury in retrograde. Archive of General Psychiatry. 2008; 65(1): 19-24.

5. Silva M, Mulick, J.A. Diagnosticando o transtorno autista: aspectos fundamentais e considerações práticas. Psicologia Ciência e Profissão. Brasília, 2009; 29(1): 116-31.

6. Buiza Navarrete J, Adrian Torres J, González Sánchez M. Marcadores neurocognitivos en el trastorno específico del lenguaje. Revista de Neurologia. 2007; 44( 6): 326-33.

http://dx.doi.org/10.1590/S1516-18462011005000075

RECEBIDO EM: 07/05/2010

ACEITO EM: 27/03/2011

Endereço para correspondência:

Ana Paula Ramos de Souza

Rua Raposo Tavares 134, apto. 401

Santa Maria - RS - Brasil

CEP: 97015-560

E-mail: ramos1964@uol.com.br
7. Liu X, Kawamura Y, Shimada T, Otowa T, Koishi $\mathrm{S}$, Sugiyama $\mathrm{T}$, Nishida $\mathrm{H}$ et al. Association of the oxytocin recepto (OXTR) gene polymorphism with autism spectrum disorder (ASD) in Japanese population. J Hum Genet. 2010; 55 (3): 137-41.

8. Catão I. O bebê nasce pela boca: voz, sujeito e clínica do autismo. São Paulo, Instituto Langage, 2009.

9.Balestro J I, Souza A P R, Rechia I. C. Terapia fonoaudiológica em três casos do espectro autístico. Revista Sociedada Brasileira de Fonoaudiologia. 2009; 14(1): 129-35.

10. Rechia IC, Souza APR. Dialogia e função materna em casos de limitações práxicas. Psicologia em Estudo, 2010; 15 (2):315-21.

11. Souza A P R De, Klinger EF, Borin L, Madaner $R$. Entrevista continuada na clínica de linguagem infantil. Fractal: revista de Psicologia. 2009; 21(3): 601-11.

12. Tamanaha A C, Chiari B M, Perissinoto J, Pedromônico M R A atividade lúdica no autismo infantil. Distúrbios da Comunicação. 2006; 18(3): 307-12.

13. De Lemos C T G. Los procesos metafóricos y metonímicos como mecanismos de cambio. Substratum, Barcelona. 1992, 1(1):121-35.

14. Laznik M C. A voz da sereia: O autismo e os impasses na constituição do sujeito. Salvador, BA: Ágalma, 2004.

15. Cesa CC, Souza APR, Kessler TM Intersubjetividade mãe-filho na experiência com comunicação ampliada e alternativa. Rev CEFAC. 2010; 12 (1): 57-67.

16. Schmidt C, Dell'Aglio DD, Bosa CA. Estratégias de coping de mães de portadores de autismo: lidando com dificuldades e com a emoção. Psicol. Reflex.Crit. 2007; 20 (1): 124-31. 